\title{
Dieta rica em proteína na redução do peso corporal
}

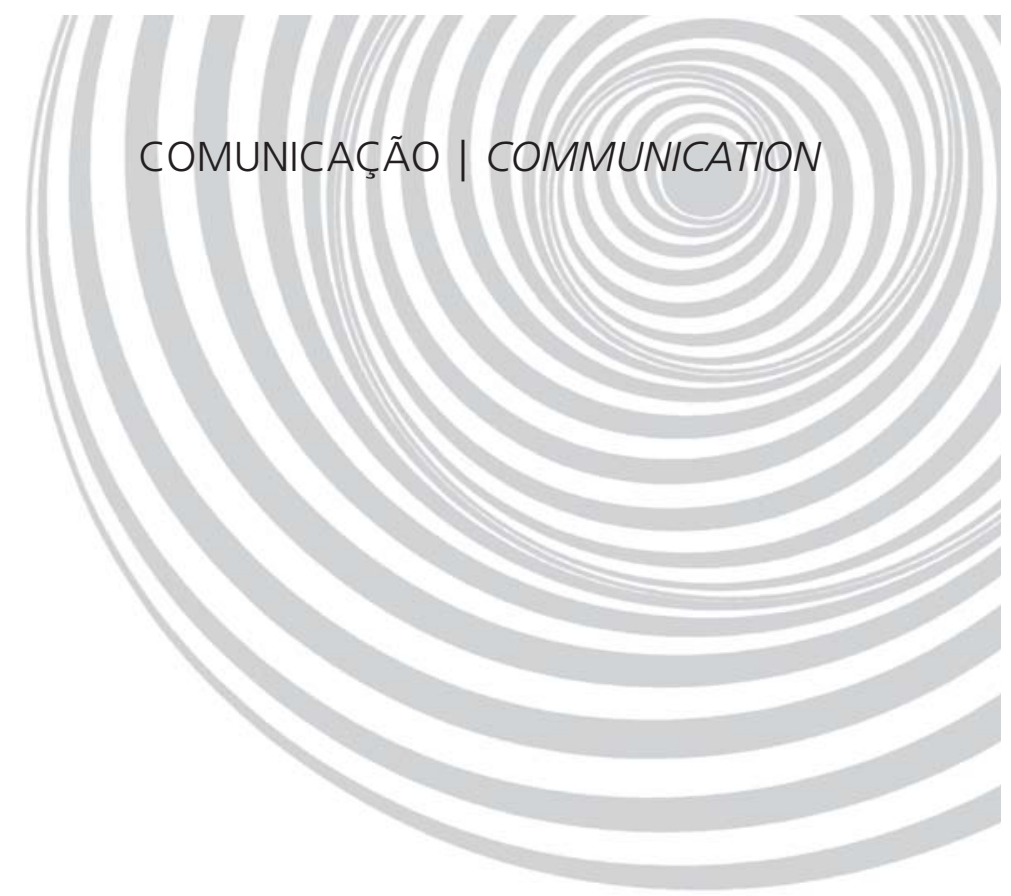

Rogerio Graça PEDROSA

Jose DONATO JUNIOR ${ }^{2}$

Julio TIRAPEGUI'

\section{RE S U M O}

A proporção ideal dos macronutrientes em dietas de emagrecimento é atualmente bastante discutida. Existem evidências de que dietas com maior proporção de proteína aumentam a perda de peso e de gordura corporal e diminuem a perda de massa corporal magra durante o emagrecimento. Todavia, os mecanismos responsáveis por estes efeitos não estão totalmente esclarecidos. Além disso, existem poucas conclusões a respeito dos possíveis efeitos colaterais dessas dietas na função renal e no estado nutricional relativo ao cálcio. Assim, este artigo objetiva trazer informações atuais sobre os efeitos de dietas ricas em proteína na perda de peso e na composição corporal e dos mecanismos envolvidos, bem como seus efeitos na função renal e no estado nutricional relativo ao cálcio.

Termos de indexação: Composição corporal. Perda de peso. Proteínas na dieta.

A B S T R A C T

The ideal proportion of macronutrients in weight loss diets is currently under debate. There are evidences indicating that a higher proportion of protein during weight loss diets enhances the loss of body weight and fat mass, and reduces the loss of lean body mass. Nevertheless, the responsible mechanisms for these effects have not yet been fully elucidated. Furthermore, studies that evaluated the possible side effects of these diets on the renal function and on the nutritional state of calcium have shown inconclusive results. Therefore, this article has the objective to convey recent information about the effects of high-protein diets in the regulation of the body weight and body composition, besides its involved mechanisms, and its effects on the renal function and on the calcium nutritional status.

Indexing terms: Body composition. Weight loss. Dietary proteins.

${ }^{1}$ Universidade de São Paulo, Faculdade de Ciências Farmacêuticas, Departamento de Alimentos e Nutrição Experimental. Av. Prof. Lineu Prestes, 580, Bloco 14, 05508-900, Cerqueira César, São Paulo, SP, Brasil. Correspondência para/Correspondence to: J. TIRAPEGUI. E-mail: <tirapegu@usp.br>.

2 Universidade de São Paulo, Instituto de Ciências Biomédicas, Departamento de Anatomia. São Paulo, SP, Brasil. 
I N T R O D U Ç Ã O

A incidência de sobrepeso e obesidade assumiu proporções epidêmicas na população mundial'1. A obesidade é caracterizada pelo acúmulo excessivo de gordura corporal, o qual traz prejuízos à saúde do indivíduo². A redução de peso corporal em indivíduos com sobrepeso (Índice de Massa Corporal - IMC de $25 \mathrm{~kg} / \mathrm{m}^{2}$ ou mais) ou obesidade (IMC de $30 \mathrm{~kg} / \mathrm{m}^{2}$ ou mais), tem sido associada com a diminuição de risco e com o controle de doenças como diabetes mellitus do tipo II e cardiopatias ${ }^{3}$. Diante dessas evidências é recomendado que indivíduos apresentando sobrepeso ou obesidade sejam submetidos a algum tratamento para perda de peso corporal, a fim de reduzir as chances de mortalidade precoce e controlar doenças relacionadas ao excesso de gordura corporal ${ }^{1,3}$

Nesse sentido, as estratégias de emagrecimento mais descritas são: dietas, exercícios físicos, fármacos, cirurgias e terapias comportamentais ${ }^{4}$. Tratamentos convencionais, como a restrição energética e o exercício físico, têm sido os mais utilizados e recomendados para perda de peso ${ }^{5}$. A restrição energética geralmente tem destaque nos programas de emagrecimento, por proporcionar maior redução de peso, sendo, muitas vezes, utilizada como única estratégia ${ }^{6}$. Todavia, a redução de peso e gordura corporal alcançada por meio da restrição energética quase sempre é acompanhada pela diminuição da massa corporal magra 5 .

Atualmente existem evidências de que dietas com maior proporção de proteína promovem maior perda de peso, maior redução de gordura corporal e diminuem a perda de massa magra durante o emagrecimento, quando comparadas a dietas com menos proteína e de mesmo valor energético ${ }^{7-10}$. Sendo assim, este estudo busca discutir este tema, além de enfocar algumas questões ainda não solucionadas, como os efeitos colaterais associados e os mecanismos envolvidos com as dietas com maior proporção de proteína.

\section{EFEITOS NA REDUÇÃO DE PESO E NA COMPOSIÇÃO CORPOR A L}

A restrição energética tipicamente recomendada para redução de peso caracteriza-se por ter grande quantidade de carboidratos, limitada quantidade de gordura e moderada quantidade de proteína, o que significa, em termos percentuais, $15 \%$ de proteína, $55 \%$ de carboidrato e $30 \%$ ou menos de gordura ${ }^{11}$. Todavia, a proporção ideal dos macronutrientes em dietas de emagrecimento é, atualmente, bastante discutida. Existem evidências de que as dietas com maior proporção de proteína e menor de carboidrato promovem maior perda de peso, maior redução de gordura corporal e menor perda de massa magra, quando comparadas às dietas convencionais ${ }^{7-10}$. Nestas dietas a proporção de proteína recomendada pode variar entre $22 \%$ a $45 \%$ do valor energético total ${ }^{11,12}$

A maior redução de peso ocasionada com dieta rica em proteína foi verificada em um estudo realizado com 65 indivíduos obesos ${ }^{7}$, no qual os indivíduos foram divididos em dois grupos: o primeiro submetido à dieta com maior proporção de proteína ( $25 \%$ do valor energético) e o segundo submetido à dieta convencional $(12 \%$ do valor energético). Os dois grupos também foram orientados a consumir uma quantidade de gordura $<30 \%$ do valor energético total e a consumir alimentos de forma ad libitum, durante um período de seis meses. Após esse período, foi constatado que o grupo de indivíduos submetidos à dieta com $25 \%$ de proteína teve perda de peso $4,3 \%$ maior do que o outro grupo. Em estudo de revisão sobre os efeitos de dietas ricas em proteína, realizado por Buchholz \& Schoeller ${ }^{13}$, foi verificado que a perda de peso ocasionada por dieta com maior proporção de proteína ou menor de carboidrato é de 2,5kg a mais, na média, quando comparada à dieta com maior proporção de carboidratos, após um período de 12 meses. Foi verificado, também, que após 24 meses, a perda de peso promovida pela dieta com maior proporção de proteína ou menor de carboidratos é, em média, de 4,0kg 
maior. Estas médias foram obtidas de estudos que avaliaram os efeitos destas dietas, tanto em indivíduos com consumo ad libitum, quanto em indivíduos submetidos à restrição energética. Cabe ressaltar que ainda há controvérsia em relação aos efeitos das dietas ricas em proteína sobre a redução de peso corporal, pois tal efeito não tem sido verificado em todos os estudos que o avaliam. Esse fato pode ser observado no estudo de revisão realizado por Halton \& $\mathrm{Hu}^{12}$, que identificaram 15 estudos que avaliaram o efeito desta dieta sobre a perda de peso. Esses autores constataram que, dos 15 trabalhos incluídos na revisão, 7 encontraram redução de peso significativa e 8 não encontraram o mesmo efeito.

Os efeitos favoráveis na composição corporal das dietas com maior proporção de proteína e menor de carboidrato foram observados em alguns estudos que adotaram a restrição energética como forma de tratamento para redução de peso, ${ }^{9,10}$. Em um trabalho que verificou o efeito de dieta com maior proporção de proteína em 57 indivíduos (14 homens e 43 mulheres) submetidos a 12 semanas de restrição energética, seguidas de mais quatro semanas de dieta normocalórica, foi observada maior preservação de massa magra, apenas nas mulheres submetidas a dieta com 27\% de proteína em relação àquelas submetidas à dieta com $16 \%$ deste macronutriente ${ }^{9}$. Nesse estudo, também foi observado que a redução de gordura corporal não diferiu entre os indivíduos submetidos às duas dietas. Já Layman et al. ${ }^{10}$ verificaram que mulheres submetidas a 16 semanas de restrição energética com dieta com maior quantidade de proteína (1,6g/kg/dia) perderam mais gordura corporal, quando comparadas a mulheres submetidas à mesma restrição energética, porém, com dieta com menor quantidade de proteína $(0,8 \mathrm{~g} / \mathrm{kg} / \mathrm{dia})$. Layman et al. ${ }^{10}$ observaram, também, que a perda de massa magra foi igual para ambos os grupos de mulheres. Pode-se notar, pelo exposto anteriormente, que existem controvérsias em relação aos efeitos, na composição corporal, das dietas com maior proporção de proteína e menor de carboidrato, fato que foi relatado, também, no estudo de revisão realizado por Halton \& $\mathrm{Hu}^{12}$. Tais autores mencionam 10 trabalhos que avaliaram os efeitos dessas dietas sobre a composição corporal; desses, apenas 3 encontraram efeitos positivos e significativos. Essa diferença em relação aos resultados encontrados pode ser uma conseqüência dos distintos protocolos utilizados nesses estudos, entre os quais merecem destaque: as diferentes proporções, quantidades e fontes de proteína, a duração do tratamento e o grau da restrição energética. Dessa maneira, mais pesquisas são necessárias para definir a melhor proporção, quantidade e a melhor fonte de proteína a ser utilizada em dietas para redução de peso, bem como o tempo ideal de tratamento e o grau de restrição energética que aperfeiçoe o efeito da maior proporção ou da quantidade deste macronutriente na dieta.

\section{EFEITOS NA FUNÇÃO RENAL E NOESTADONUTRICIONAL RELATIVOAO CÁLCIO}

Embora existam evidências em relação aos efeitos favoráveis da dieta com maior proporção de proteína na redução de peso e na composição corporal, existem poucas conclusões a respeito dos possíveis efeitos colaterais dessa maior ingestão protéica em indivíduos saudáveis ${ }^{11,14,15}$. Entre os possíveis efeitos colaterais da maior ingestão protéica os mais investigados são em relação à função renal e ao estado nutricional relativo ao cálcio. Eisenstein et al. ${ }^{11}$ concluíram, em um estudo de revisão, que existem poucas evidências do efeito deletério da dieta com maior proporção ou quantidade de proteína na função renal, mas sugerem precaução em relação ao uso destas dietas em indivíduos com evidências de doença renal, diabéticos e com histórico de nefrolitíase. Estudos mais recentes ${ }^{8,14}$, que avaliaram o efeito da maior ingestão protéica na função renal de indivíduos em curto prazo (10 e 6 semanas, respectivamente), não encontraram diferença nesta função, quando os resultados foram comparados 
aos obtidos de indivíduos com menor ingestão protéica. A maior ingestão protéica em longo prazo tem sido induzida, apenas, em animais de experimentação. Lacroix et al. ${ }^{15}$ não observaram dano na função renal de ratos que consumiram dieta com 50\% de proteína durante 6 meses. No entanto, esses autores enfatizam que os resultados encontrados não podem ser extrapolados para os humanos, pelo fato de os roedores terem maior capacidade de concentrar uréia. Assim, mais estudos são necessários para avaliar o efeito, principalmente em longo prazo, da dieta com maior proporção ou quantidade de proteína na função renal de indivíduos saudáveis durante período de perda de peso.

Outro efeito colateral que pode estar associado à maior ingestão protéica por indivíduos saudáveis é a maior excreção urinária de cálcio. A hipercalciúria, ocasionada pela maior ingestão de proteína, é uma conseqüência do aumento da produção de ácido que ocorre durante a oxidação de aminoácidos sulfurados, que são encontrados, principalmente, em proteínas de origem animal. A maior produção de ácido está relacionada ao aumento da taxa de filtração glomerular e à diminuição da reabsorção tubular de cálcio, eventos que podem resultar no balanço negativo do cálcio e na reabsorção óssea ${ }^{11}$. No entanto, ressalta-se que os resultados dos estudos que avaliaram os efeitos da maior ingestão protéica em parâmetros indicativos do estado nutricional de cálcio e da renovação óssea, são controversos. Eisenstein et al. ${ }^{11}$ revisaram estudos que encontraram associação entre a maior ingestão de proteína, em curto prazo e o aumento da excreção urinária de cálcio o balanço negativo do cálcio e a reabsorção óssea. Por outro lado, estudos recentes não encontraram efeitos deletérios da dieta com maior proporção ou quantidade de proteína no estado nutricional relativo ao cálcio e em parâmetros indicativos da renovação óssea de indivíduos saudáveis, que foram submetidos à redução de peso durante um período de 6 e 12 semanas $^{14,16}$. Adicionalmente, relata-se que estudos que avaliaram os efeitos, em longo prazo, da maior ingestão protéica na renovação óssea apresen- taram resultados conflitantes ${ }^{11}$. Assim, o nível superior para ingestão de proteína que esteja relacionado ao menor efeito deletério no metabolismo ósseo precisa ainda ser definido.

\section{MECANISMOS}

O mecanismo pelo qual a dieta com maior proporção de proteína aumenta a redução de peso em relação à dieta convencional ainda não está esclarecido. Uma das hipóteses está relacionada ao maior efeito da proteína na saciedade, quando comparado ao do carboidrato. Sabe-se que a saciedade é regulada pela complexa interação de mecanismos fisiológicos, psicológicos e comportamentais ${ }^{12}$. No estudo realizado por Skov et al. ${ }^{7}$, citado anteriormente, a maior redução de peso promovida pela dieta rica em proteína foi atribuída ao maior efeito deste nutriente na saciedade, uma vez que a ingestão energética dos indivíduos que realizaram esta dieta foi $17 \%$ menor, quando comparada à dos indivíduos com dieta com menos proteína. Resultado semelhante foi encontrado em estudo que submeteu dois grupos de ratos a seis meses de consumo ad libitum de ração com 14 ou $50 \%$ de proteína ${ }^{15}$. Neste estudo, foi observado que o grupo de animais que consumiu a ração com mais proteína teve consumo de ração 18\% menor, após os seis meses de experimento. Todavia, como observado por Buchholz \& Schoeller ${ }^{13}$, o maior efeito da proteína na saciedade não pode ser considerado como explicativo, em alguns estudos, para a maior perda de peso corporal ocasionada pela dieta com maior proporção deste macronutriente. Isto se deve ao fato de que nesses estudos a ingestão energética foi igual para os indivíduos que realizaram as dietas com maior ou menor proporção de proteína.

Outro mecanismo proposto para explicar o efeito da dieta rica em proteína na redução de peso é o relacionado ao maior efeito desta dieta na termogênese, mais especificamente no efeito térmico dos alimentos (ETA) ${ }^{11,13}$. O ETA consiste no aumento do gasto energético observado após a ingestão de uma refeição. Esse aumento no 
gasto energético pós-prandial é necessário para a realização dos processos de digestão, absorção e metabolismo dos nutrientes ingeridos, podendo representar, aproximadamente, de 5 a $10 \%$ do gasto energético diário de um indivíduo ${ }^{17}$. O ETA produzido pela proteína pode ser de 20 a 35\% do conteúdo energético ingerido, enquanto que o do carboidrato fica entre 5 e $15 \%$ e o da gordura fica entre 0 e $5 \%{ }^{12,18}$. A maior influência da proteína no ETA se deve ao fato de que este macronutriente não pode ser armazenado pelo organismo, tal como acontece com os carboidratos e as gorduras, precisando ser metabolizado imediatamente após sua ingestão. Durante o metabolismo das proteínas a energia pode ser utilizada, principalmente, nas reações de síntese protéica, síntese de uréia e neoglicogênese ${ }^{12}$. A maior influência da proteína no ETA foi observada no estudo realizado por Robinson et al. ${ }^{19}$. Nesse estudo foi observado que, após uma refeição rica em carboidratos, 36\% do ETA produzido foi destinado à síntese protéica, e que após uma refeição rica em proteína, este valor foi de 68\%. Dessa forma, o estudo sugere que a maior parte do ETA produzido pela ingestão de uma refeição rica em proteína pode ser destinada à síntese protéica.

As evidências não deixam dúvidas quanto à maior influência da dieta com maior proporção ou quantidade de proteína no ETA, quando comparada à influência da dieta convencional com mesmo valor energético. Mas existem dúvidas em relação à repercussão dessa influência ou de sua magnitude na redução de peso corporal. Acredita-se que o maior ETA provocado pela dieta com maior proporção de proteína seja responsável por apenas um terço do excedente de peso corporal perdido por indivíduos em uso desta dieta. Ou seja, dos 2,5kg de peso corporal perdidos a mais por esses indivíduos, após período de 12 meses, apenas 0,8kg são atribuídos ao maior ETA desta $\operatorname{dieta}^{13}$. Dessa maneira, mais estudos são necessários para o total esclarecimento dos mecanismos responsáveis pelos efeitos da dieta rica em proteína na redução de peso corporal.

Da mesma forma, os mecanismos relacionados aos efeitos da dieta rica em proteína na composição corporal ainda não são conhecidos. Todavia, algumas hipóteses foram propostas para explicar tal efeito, entre estas: 1) manutenção das concentrações dos hormônios tireoidianos T3 e T4 durante a redução de peso; 2) menor resposta insulinêmica ocasionada pela menor quantidade de carboidrato na dieta (perfil endócrino associado ao estímulo à lipólise) e 3) preservação da proteína corporal durante o emagrecimento ${ }^{8,10}$. Assim, o conjunto desses efeitos da dieta com maior proporção de proteína resultariam no aumento da oxidação de gordura e na preservação da massa magra durante a redução de peso corporal. Também é sugerido que parte dos benefícios promovidos pela dieta com maior proporção de proteína na composição corporal pode ser atribuída à maior ingestão de aminoácidos de cadeia ramificada $(A C R)$, leucina, isoleucina e valina ${ }^{20,21}$. Estes aminoácidos são considerados essenciais pelo fato de não serem sintetizados no organismo. Atualmente, existem evidências de que os ACR desempenham papel fundamental na regulação de processos anabólicos envolvendo a proteína, modulando tanto a síntese quanto a degradação deste componente corporal22. Dessa forma, segundo esta hipótese, a maior oferta de proteína não seria apenas para aumentar a disponibilidade de substratos (aminoácidos) para a síntese protéica, mas, também, para estimular processos anabólicos que são observados a partir da maior ingestão dos $A C R$, particularmente do aminoácido leucina.

Existem evidências in vitro e in vivo de que a leucina é capaz de estimular a síntese protéica, por ativar, principalmente, o início do processo de tradução protéica ${ }^{23-25}$. O início da tradução protéica é uma das principais etapas que regulam a síntese de proteínas, pois determina a eficiência com que o aparato ribossomal é utilizado na tradução do RNA mensageiro ${ }^{26}$. Além disso, a leucina aumenta a quantidade de proteínas ribossomais e fatores de elongação, resultando em maior capacidade de síntese protéica celular ${ }^{23,24}$. Todavia, a maior parte desses estudos avaliou apenas os efeitos agudos da administração de leucina. O efeito da suplementação crônica foi verificado em um 
estudo realizado com ratos suplementados com leucina durante 12 dias, no qual se observou aumento na taxa de síntese protéica no tecido adiposo, no músculo gastrocnêmio e no fígado ${ }^{25}$. Outro estudo, que avaliou o efeito da suplementação crônica com leucina em ratos, verificou maior retenção de nitrogênio na carcaça desses animais, após fase de recuperação nutricional de 60 dias com dieta rica em leucina, a qual foi antecedida de outra fase de 60 dias de desnutrição protéica ${ }^{27}$. O efeito da suplementação crônica de leucina sob a condição catabólica foi avaliado em estudo que submeteu ratos à restrição alimentar de $50 \%$, durante seis semanas ${ }^{28}$. Nesse experimento não foi observada preservação do conteúdo de massa magra e de proteína na carcaça de animais suplementados com leucina, quando comparados aos animais sem suplementação. Entretanto, observou-se menor conteúdo de gordura na carcaça dos animais suplementados. Resultado semelhante foi encontrado no estudo realizado por Mourier et al. ${ }^{29}$, que avaliaram o efeito da suplementação crônica dos ACR em lutadores submetidos a 19 dias de restrição energética. Nesse estudo, foi observado que a restrição energética, aliada à suplementação com ACR foi mais efetiva na redução da gordura corporal, quando comparada à restrição energética isolada. Não foram, porém, observadas mudanças significativas na massa magra e no peso corporal desses atletas. Dessa forma, fica evidente a necessidade de mais estudos para o esclarecimento dos mecanismos responsáveis pelos efeitos da dieta rica em proteína na composição corporal.

\section{CONSIDERAÇÕES FINAIS}

Existem evidências de que a dieta com maior proporção de proteína aumenta a perda de peso e de gordura corporal e diminui a perda de massa corporal magra durante o emagrecimento. Entretanto, mais estudos são necessários para definir a melhor proporção, a quantidade e a fonte de proteína a ser utilizada em dietas para redução de peso, bem como o tempo ideal de tratamento e o grau de restrição energética que aperfeiçoe o efeito da maior proporção ou da quantidade deste macronutriente na dieta. Além disso, questões como efeitos colaterais associados e mecanismos envolvidos com as dietas com maior proporção de proteína necessitam de maiores esclarecimentos.

\section{A GRADECIMENTOS}

Os autores agradecem à Fundação de Amparo à Pesquisa do Estado de São Paulo (05/58997-4) e ao Conselho Nacional de Desenvolvimento Científico e Tecnológico, pelas bolsas de pesquisa outorgadas.

\section{OLABORAÇ Ã O}

R.G. PEDROSA participou do desenho, da concepção, da redação e da revisão do manuscrito. J.D. JUNIOR participou do desenho, da concepção, da redação e da revisão do manuscrito. J. TIRAPEGUI participou do desenho, da concepção, da redação e da revisão do manuscrito.

\section{REFER Ê N CIAS}

1. Kopelman PG. Obesity as a medical problem. Nature. 2000; 404(6778):635-43.

2. Pi-Sunyer FX. Obesity: criteria and classification. [Symposium on 'Body weight regulation and obesity: metabolic and clinical aspects' 1st Plenary Session: 'Obesity']. Proc Nutr Soc. 2000; 59(4): 505-9.

3. Expert Panel on the Identification, Evolution, and Treatment of Overweight in Adults. Clinical guidelines on the identification, evolution, and treatment of overweight and obesity in adults: executive summary. Am J Clin Nutr. 1998; 68(4): 899-917.

4. Fujioka K. Management of obesity as a chronic disease: nonpharmacologic, pharmacologic, and surgical options. Obes Res. 2002; 10(Suppl 2): 116-23.

5. Garrow JS, Summerbell CD. Meta-analysis: effect of exercise, with or without dieting, on the body composition of overweight subjects. Eur I Clin Nutr. 1995; 49(1):1-10.

6. Distschuneit HH, Flechtnes-Mors M, Johnson TD, Adler G. Metabolic and weight-loss effects of a 
long-term dietary intervention in obese patients. Am J Clin Nutr. 1999; 69(2):198-204.

7. Skov AR, Toubro S, Ronn B, Holm L, Astrup A. Randomized trial on protein vs carbohydrate in ad libitum fat reduced diet for the treatment of obesity. Int J Obes. 1999; 23(5):558-36.

8. Layman DK, Boileau RA, Erickson DJ, Painter JE, Shiue $H$, Sather $C$, et al. A reduced ratio of dietary carbohydrate to protein improves body composition and blood lipid profiles during weight loss in adult women. J Nutr. 2003; 133(2): 411-7.

9. Farnsworth E, Luscombe ND, Noakes M, Wittert G, Argyiou E, Clifton PM. Effect of a high-protein, energy-restricted diet on body composition, glycemic control, and lipid concentrations in overweight and obese hyperinsulinemic men and women. Am J Clin Nutr. 2003; 78(1):31-9.

10. Layman DK, Evans E, Baum Jl, Seyler J, Erickson DJ, Boileau RA. Dietary protein and exercise have additive effects on body composition during weight loss in adult women. J Nutr 2005; 135(8): 1903-10.

11. Eisenstein J, Roberts SB, Dallal G, Saltzman E. High-protein weight-loss diets: are they safe and do they work? A review of the experimental and epidemiologic data. Nutr Rev. 2002; 60(7 Pt 1): $189-200$

12. Halton TL, Hu FB. The effects of high protein diets on thermogenesis, satiety and weight loss: a critical review. J Am Coll Nutr. 2004; 23:373-85.

13. Buchholz AC, Schoeller DA. Is calorie a calorie? Am J Clin Nutr. 2004; 79(5):899-906.

14. Johnston CS, Tjonn SL, Swan PD. High-protein, low-fat diets are effective for weight loss and favorably alter biomarkers in healthy adults. J Nutr. 2004; 134(3):586-91.

15. Lacroix M, Gaudichon C, Martin A, Morens C, Mathé $\mathrm{V}$, Tomé $\mathrm{D}$, et al. A long-term high-protein diet markedly reduces adipose tissue without major side effects in Wistar male rats. Am J Physiol Regul Integr Comp Physiol. 2004; 287(4):934-42.

16. Noakes M, Keogh JB, Foster PR, Clifton PM. Effect of an energy-restricted, high-protein, low-fat diet relative to a conventional high-carbohydrate, low-fat diet on weight loss, body composition, nutrition status, and markers of cardiovascular health in obese women. Am J Clin Nutr. 2005; 81(6):1298-306.

17. Poehlman ET, Horton ES. The impact of food intake and exercise on energy expenditure. Nutr Rev. 1989; 47(5):129-37.
18. Westerterp KR, Wilson SAJ, Rolland V. Diet induced thermogenesis over $24 \mathrm{~h}$ in a respiration chamber: effect of diet composition. Int J Obes. 1999; 23(3):287-92.

19. Robinson SM, Jaccard C, Persaud C, Jackson AA, Jequier E, Schutz Y. Protein turnover and thermogenesis in response to high-protein and high-carbohydrate feeding in men. Am J Clin Nutr. 1990; 52(1):72-80.

20. Layman KL. The role of leucine in weight loss diets and glucose homeostasis. J Nutr. 2003; 133(1): 261-7.

21. Layman KL, Walter DA. Potential importance of leucine in treatment of obesity and the metabolic syndrome. J Nutr. 2006; 136(1 Suppl):319-23.

22. Tom A, Nair KS. Assessment of branched-chain amino acid status and potential for biomarkers. J Nutr. 2006; 136(1 Suppl):324-30.

23. Patti ME, Brambilla E, Luzi L, Landaker EJ, Kahn CR. Bidirectional modulation of insulin action by amino acids. J Clin Invest. 1998; 101(7):1519-29.

24. Anthony JC, Anthony TG, Kimball SR, Jefferson LS. Signaling pathways involved in translational control of protein synthesis in skeletal muscle by leucine. J Nutr. 2001; 131(3):856-60.

25. Lynch CJ, Patson BJ, Anthony J, Vaval A, Jefferson LS, Vary TC. Leucine is a direct-acting nutrient signal that regulates protein synthesis in adipose tissue. Am J Physiol Endocrinol Metab. 2002; 283(3): 503-13.

26. Millward DJ, Waterlow JC. Effect of nutrition on protein turnover in skeletal muscle. Fed Proc. 1978; 37(9):2283-90

27. Ventrucci G, Silva LGR, Mello MAR, Marcondes MCG. Effects of a leucine-rich diet on body composition during nutritional recovery in rats. Nutrition. 2004; 20(2):213-7.

28. Donato Jr J, Pedrosa RG, Vinicius F, Cruzat VF, Pires ISO, Tirapegui J. Effects of chronic leucine supplementation on the body composition and protein nutritional status of adult rats submitted to food restriction. Nutrition. 2006; 22(5):520-27.

29. Mourier A, Gautier JF, Kerviler E, Bigard AX, Villette JM, Garnier JP, et al. Mobilization of visceral adipose tissue related to the improvement in insulin sensitivity in response to physical training in NIDDM. Effects of branched-chain amino acid supplements. Diabetes Care. 1997; 20(30):385-91.

Recebido em: 12/3/2007

Versão final reapresentada em: 18/12/2007 Aprovado em: 2/11/2008 
